\title{
Editorial
}

\section{Xylanase Supplementation in Wheat-based Diets and the Influence on Necrotic Enteritis in Broilers: A Translational Model for Human Malnutrition}

\author{
Beer Lesleigh, MSc'; Butler Leasea, MSc'; Gautier Alyson, MSc'; Graham Danielle, MSc'; Teague Kyle, MSc'; Wilson Venus, BSc²; Sami \\ Dridi, PhD $^{1^{*}}$
}

'Department of Poultry Science, Division of Agriculture, University of Arkansas, Fayetteville, AR 7270I, USA

"Corresponding author

Sami Dridi, PhD

Center of Excellence for Poultry Science, University of Arkansas, I260 W, Maple Street, Fayetteville AR 7270I, USA; Tel. (479)-575-2583; Fax: (479)-575-7I 39;

E-mail: dridi@uark.edu

\section{Article information}

Received: October $7^{\text {th }}$ 2018; Accepted: October II th 2018 ; Published: October $16^{\text {th }}, 2018$

\section{Cite this article}

Beer L, et al. Xylanase supplementation in wheat-based diets and the influence on necrotic enteritis in broilers: A translational model for human malnutrition. Adv Food Technol Nutr Sci Open J. 2018; 4(2): e4-e5. doi: 10.17I40/AFTNSOJ-4-e0I3

I Th the poultry industry, necrotic enteritis results in substantial 1 production and economic losses each year. Outbreaks are more prevalent due to the removal of antibiotic growth promoters. ${ }^{1}$ Clostridium perfringens, a commensal organism within the gastrointestinal tract of poultry, is the primary bacterial etiology responsible for necrotic enteritis. ${ }^{2}$ In the absence of a host, C. perfringens spores can remain dormant in the environment for long durations, possibly between flocks. ${ }^{3}$ Eimeria spp. colonization commonly predisposes broilers to the disease due to epithelial cell damage and increased mucus production, which provides an ideal environment for proliferation of C. perfringens. ${ }^{4}$ Dietary ingredients, such as wheat can affect the integrity of the gastrointestinal tract and potentially induce necrotic enteritis.,

Wheat is a variable feed grain that is high in insoluble non-starch polysaccharides. ${ }^{6}$ Non-starch polysaccharides fed in moderate amounts can slow passage rates due to the gizzard's ability to retain insoluble fiber. ${ }^{7}$ High-levels of non-starch polysaccharides present in wheat diets can increase viscosity in the small intestine due to their lack of digestibility. ${ }^{6}$ According to Branton et al broilers challenged with $C$. perfringens and fed wheatbased diets had higher necrotic enteritis lesion scores than the challenged and non-challenged corn-based diet controls. ${ }^{5}$

Research studies have shown that enzyme addition to broiler diets can mitigate the negative effects of necrotic enteritis and improve growth performance. ${ }^{8}$ Moreover, xylanase supplementation to poultry diets is widely accepted as this enzyme functions to break down arabinoxylans located within plant cell walls, producing greater nutrient bioavailability and reducing negative non-starch polysaccharides. ${ }^{6}$ Within wheat-based broiler diets, supplementation of xylanase has been shown to increase apparent metabolizable energy, improve ileal nutrient digestibility, decrease ileal digesta viscosity, reduce feed conversion ratio, and diminish levels of $C$. perfringens. ${ }^{9,10,11}$ Additionally, xylanase supplementation to wheat-based diets may alleviate damage inflicted by necrotic enteritis upon the intestinal mucosal barrier partly through protective mechanisms which contribute to the reduction of apoptotic epithelial cells and intestinal permeability. ${ }^{12}$ Taken together, these results indicate the positive impacts that the inclusion of enzymes such as xylanase appear to have upon the growth performance of broilers, leading to a potentially significant economical contribution.

The utilization of xylanase within animal feed for improved growth performance suggests a potential area of nutritional improvement through poultry production as an efficient protein source to feed the future. Furthermore, xylanase is a naturally-occurring enzyme that can have beneficial impacts on human health and digestion through the degradation of fiber, although humans are unable to synthesize xylanase and must rely on microorganisms. Additionally, xylanases might offer some benefit within the food industry, particularly for the acceleration of bakery products. ${ }^{13}$ Therefore, the use of supplemental xylanase can be potentially beneficial, especially in malnourished countries, to support the breakdown of fiber and further utilization of previously inaccessible nutrients. Xylanase has been extensively used in the baking industry leading to an increase in bread volumes, greater absorption of water, and improved resistance to fermentation. ${ }^{14,15}$ Additionally, the fiber-breaking enzymes are capable of hydrolyzing the non- digestible carbohydrates that bind and compromise fiber utilization. Therefore, xylanase can be a digestive aid to improve the nutritional value and digestion of fibrous foods. 


\section{CONFLICTS OF INTEREST}

The authors declare that they have no conflicts of interest.

\section{REFERENCES}

1. Huyghebaert G, Ducatelle R, and Immerseel VF. An update on alternatives to antimicrobial growth promoters for broilers. Vet. J. 2011; 187(2): 182-188. doi: 10.1016/j.tvj1.2010.03.003

2. Timbermont L, Haesebrouck F, Ducatelle R, Immerseel VF. Necrotic enteritis in broilers: an updated review on the pathogenesis. Avian Pathol. 2011; 40(4): 341-347. doi: 10.1080/03079457.2011.590967

3. Prescott JF, Parreira VR, Mehdizadeh Gohari I, Lepp D, Gong J. The pathogenesis of necrotic enteritis in chickens: what we know and what we need to know: a review. Avian Pathol. 2016; 45(3): 288294. doi: 10.1080/03079457.2016.1139688

4. Collier CT, Hofacre CL, Payne AM, et al. Coccidia-induced mucogenesis promotes the onset of necrotic enteritis by supporting Clostridium perfringens growth. Vet Immunol Immunopathol. Immunopathol. 2008; 122(1-2): 104-115. doi: 10.1016/j. vetimm.2007.10.014

5. Branton SL, Lott BD, Deaton JW, et al. The effect of added complex carbohydrates or added dietary fiber on necrotic enteritis lesions in broiler chickens. Poult Sci. 1997; 76(1): 24-28. doi: $10.1093 / \mathrm{ps} / 76.1 .24$

6. Amerah A. Interactions between wheat characteristics and feed enzyme supplementation in broiler diets. Animal Feed Science and Technology. 2015; 199: 1-9. doi: 10.1016/j.anifeedsci.2014.09.012

7. Hetland H, Choct M, Svihus B. Role of insoluble non-starch polysaccharides in poultry nutrition. World's Poultry Science Journal. 2004; 60(4): 415-422. doi: 10.1079/WPS200325
8. Jia W, Slominski BA, Bruce HL, et al. Effects of diet type and enzyme addition on growth performance and gut health of broiler chickens during subclinical clostridium perfringens challenge. Poult Sci. 2009; 88(1):132-140. doi: 10.3382/ps.2008-00204

9. Choct M, Sinlae M, Al-Jassim RAM, Pettersson D. Effects of xylanase supplementation on between-bird variation in energy metabolism and the number of clostridium perfringens in broilers fed a wheat-based diet. Australian Journal of Agricultural Research. 2006; 57(9): 1017-1021. doi: 10.1071/AR05340

10. Liu WC, Kim IH. Effects of dietary xylanase supplementation on performance and functional digestive parameters in broilers fed wheat-based diets. Poult Sci. 2017; 96(3): 566-573. doi: 10.3382/ps/ pew258

11. Gonzalez-Ortiz G, Sola-Oriol D, Martinez-Mora M, Perez JF, Bedford MR. Response of broiler chickens fed wheat-based diets to xylanase supplementation. Poult Sci. 2017; 96(8): 2776-2785. doi: $10.3382 / \mathrm{ps} / \mathrm{pex} 092$

12. Liu D, Guo S, Guo Y. Xylanase supplementation to a wheatbased diet alleviated the intestinal mucosal barrier impairment of broiler chickens challenged by Clostridium perfringens. Avian Pathol. 2012; 41(3): 291-298. doi: 10.1080/03079457.2012.684089

13. Harris AD, Ramalingam C. Xylanases and its application in food industry: A review. Journal of Experimental Sciences. 2010; 1(7): $1-11$.

14. Harbak L, Thygesen HV. Safety evaluation of a xylanase expressed in Bacillus subtilis. Food Chem Toxicol. 2002; 40(1): 1-8.

15. Camacho NA, Aguilar OG. Production, purification and characterization of a low-molecular-mass xylanase from Aspergillus sp. and its application in baking. Appl Biochem Biotechnol. 2003; 104(3): 159-172. 